\title{
Kegiatan Public Relations Votrro Coffee And Bar Dalam Menjaga Loyalitas Customer Votrro Coffee And Bar
}

\author{
Jeffrey, Ahmad Junaedi \\ jeffreycou088@gmail.com,ahmadd@fikom.untar.ac.id \\ Fakultas Ilmu Komunikasi Universitas Tarumanagara
}

\begin{abstract}
This research explores the Public Relations activities carried out by Votrro Coffee and Bar in maintaining customer loyalty at Votrro Coffee and Bar. The purpose of this research is to describe how Votrro Coffee and bar in carrying out Public Relatuins activities to encourage the creation of Customer Loyalty to benefit Votrro Coffee and Bar. In this study using several theories including communication theory, public relations, public relations activities, and loyalty. Research that uses qualitative descriptive methods shows that Public Relations activities are very influential for the company. To complete this study, researchers conducted in-depth interviews with six informants, namely Public Relations Votrro Coffee and Bar, Public Relations Votrro Coffee and Bar, Barista Time Votrro Coffee and Bar, four customers remain in the coffee shop, by conducting observations, library research. The results of this study are about public relations Votrro Coffee and Bar in carrying out public relations and Customer Relations activities to maintain satisfaction until the formation of customer loyalty.
\end{abstract}

Keywords: Public Relations, Customer Loyalty, Customer Relations

\begin{abstract}
Abstrak
Penelitian ini menggali tentang kegiatan Public Relations yang dilakukan Votrro Coffee and Bar dalam menjaga loyalitas customer Votrro Coffee and Bar. Tujuan dilakukannya penelitian ini adalah menjabarkan bagaimana Votrro Coffee and bar dalam menjalankan kegiatan Public Relations untuk mendorong terciptanya loyalitas customer untuk mendapatkan keuntungan bagi Votrro Coffee and Bar. Dalam penelitian ini menggunakan beberapa teori antara lain teori komunikasi, public relations, kegiatan public relations, dan loyalitas. Penelitian yang menggunakan metode deskriptif kualitatif ini menunjukkan bahwa kegiatan Public Relations sangat berpengaruh untuk bagi perusahaan. Untuk menyelesaikan penelitian ini peneliti melakukan wawancara mendalam kepada enam narasumber yaitu Public Relations Votrro Coffee and Bar, Public Relations Votrro Coffee and Bar, barista time Votrro Coffee and Bar, empat customer tetap koultoura coffee shop, dengan melakukan observasi, studi kepustakaan. Hasil dari penelitian ini adalah tentang public relations Votrro Coffee and Bar dalam menjalani kegiatan public relations dan Customer Relations untuk mempertahankan kepuasan sampai terbentuknya loyalitas customer.
\end{abstract}

Kata Kunci : Public Relations, Loyalitas Customer, Customer Relations

\section{Pendahuluan}

Persaingan pasar dalam dunia bisnis sangat ini sangat pesat. Seiring dengan perkembangan globalisasi, banyak perusahaan memutar otak bagaimana cara meningkatkan kualitas pelayanan untuk menjaga loyalitas konsumen. Karena Customer yang loyal tidak akan mencari atau berpindah pada produk yang lain dengan mudah. 
Kepuasan konsumen harus sangat dijaga untuk kelancaran atau kesuksesan dalam bisnis perusahaan tersebut. Dengan adanya kepuasan dari customer dapat tercipta hubungan harmonis antar perusahaan dengan pelanggan, jika customer merasa puas akan pelayanan perusahaan maka customer akan ada Repeat Order produk perusahaan kembali, lalu memberikan rekomendasi untuk orang-orang terdekat dari konsumen tersebut.

Faktor pelayanan merupakan ujung tombak eksistensi setiap perusahaan, memberikan kemudahan kepada konsumen dalam transaksi jualbeli, juga merupakan salah satu upaya setiap perusahaan untuk mempertahankan pelanggan, bahkan merangkul pelanggan baru bagi perusahaan.

Perkembangan gaya hidup di Indonesia jaman sekarang cenderung menyenangi produk instan yang mengakibatkan bertambahnya pengusaha yang menciptakan produk yang praktis untuk memenuhi keinginan konsumen. Sehingga menyebabkan berkembangnya industri Coffee Shop di Indonesia.

Dengan berkembangnya kopi modern yang dapat terlihat di pusat-pusat perkotaan sehingga menimbulkan tingkat konsumsi kopi masyarakat perkotaan di banding pedesaan.

Sebagai negara pertanian, pertumbuhan ekonomi nasional Indonesia dipengaruhi oleh pertumbuhan sektor pertanian dimana peran sektor pertanian lebih tinggi dibandingkan beberapa sektor lainnya.

Meningkatnya konsumsi kopi dan perubahan gaya hidup masyarakat menyebabkan mulai berkembangnya industri Coffee Shop di Indonesia. Perkembangan kedai kopi modern ini dapat terlihat di pusat-pusat perkotaan karena penduduk perkotaan memiliki sikap konsumtif yang lebih tinggi dibandingkan dengan penduduk pedesaan.

Jakarta adalah ibu kota Indonesia yang mempunyai tingkat kepadatan penduduk yang lebih di banding kota lain. Oleh karena itu Jakarta salah satu kota yang cocok untuk dijadikan tempat untuk menjalani bisnis dalam bidang coffee Shop. Berdasarkan penjelasan diatas, maka tujuan dalam penelitian ini adalah untuk mengetahui kegiatan apa yang telah dilakukan Votrro Coffee and Bar untuk mendapatkan Loyalitas Customer untuk mendapatkan keuntungan bagi Votrro Coffee and Bar.

\section{Landasan Teori}

\section{Public Relations}

Menurut Jefkins (2003) mengatakan bahwa Public Relations adalah komunikasi yang terencana, ke dalam maupun keluar antara perusahaan dengan semua khalayak untuk mencapai tujuan-tujuan dan saling pengertian.

Menurut Rhenald Kasali (2006) mengatakan bahwa Public Relations adalah fungsi managemen yang mengevaluasi sikap-sikap public, mengidentifikasi kebijakan dan prosedur perusahaan kepada publiknya, menyusun rencana, serta menjalankan program-program komunikasi dalam memperoleh pemahaman dan penerimaan public.

\section{Fungsi Public Relations}

Fungsi humas yang tercantum dalam booklet PRSA (Public Relations Society of America) dengan judul Careers in Public Relations terdapat didalam buku Introduction to Public Relations, dapat memberikan gambaran yang lebih khusus. 
Menurut Cutlip, Center, Broom didalam buku Introduction to Public Relations (2005).

Public Relations adalah membantu manajemen dalam melaksanakan kebijaksanaakebijaksanaan dan mengembangkan hubungan yang baik dengan berbagai macam publik. Public Relations adalah membantu manajemen dalam melaksanakan kebijaksanaa-kebijaksanaan dan mengembangkan hubungan yang baik dengan berbagai macam publik.

\section{Tujuan Public Relations}

Menurut Frank Jefkins (2003) mendefinisikan dari sekian banyak hal yang bisa dijadikan tujuan Public Relations sebuah perusahaan, beberapa untuk mencapai keberhasilan Public Relations mempunyai tujuan dalam peran. Tujuan merupakan sesuatu yang mengarahkan kegiatan Public Relations sehingga tidak melenceng atau salah sasaran (Kriyantono, 2012). Secara keseluruhan tujuan dari Public Relations adalah untuk menciptakan citra baik perusahaan sehingga dapat menghasilkan kesetiaan public terhadap produk yang ditawarkan oleh perusahaan (Mulyana, 2007)

\section{Metode Penelitian}

Teknik analisis yang digunakan dalam penelitian ini adalah teknik analisis kualitaif. Analisis data kualitatif adalah upaya yang dilakukan dengan jalan bekerja dengan data, mengorganisasikan data, memilah-milahnya menjadi satuan yang dapat dikelola, mensintesiskannya, mencari dan menemukan pola, menemukan apa yang penting dan apa yang dipelajari, dan memutuskan apa yang dapat diceritakan kepada orang lain (Moleong, 2013).

Narasumber yang sudah memenuhi syarat akan dijadikan sebagai informan untuk tujuan penelitian, karena memiliki yang baik terhadap masalah yang berkaitan. Sebagai informan yang dipilih untuk penelitian ini ada dua yaitu:

1. Public Relations: Nico / 24 tahun

2. Barista: Ben / 25 tahun

3. Konsumen:
a. Konsumen pertama: Steven / 21 tahun / mahasiswa
b. Konsumen kedua: Handoko / 26 tahun / karyawan swasta
c. Konsumen ketiga: Adrian / 26 tahun / karyawan swasta
d. Konsumen keempat: Shinta / 30 tahun / karyawan swasta

\section{Hasil Pembahasan Dan Penelitian}

Hasil temuan penelitian melalui wawancara mendalam dengan key informan dan informan langsung pada Votrro Coffee and Bar kurang lebih selama satu bulan, hasil penelitian dalam skripsi ini dapat diberikan kesimpulan sebagai berikut:

1. Kegiatan Public relations merupakan hal yang penting bagi setiap perusahaan untuk menjalin hubungan yang baik dengan pelanggan. Bagi sebuah organisasi atau perusahaan hubungan baik dengan pelanggannya dapat memberikan keuntungan bagi perusahaan dalam jangka panjang, oleh karena itu kegiatan Public relations sangat diperlukan oleh Votrro Coffee and Bar untuk membangun hubungan baik dengan pelanggannya. 
2. Votrro Coffee and Bar dalam mendorong loyalitas customer menerapkan kegiatan Public Relations melalui kegiatan:
a. Hubungan internal
b. Hubungan eksternal
c. Publisitas
d. Advertising
e. Public affairs

3. Public relations Votrro Coffee and Bar menyadari betul bahwa dalam memelihara loyalitas customer maka perlu menerapkan customer relations.

4. Kegiatan public relations yang dilakukan Votrro Coffee and Bar telah berhasil menarik minat beli, memenuhi harapan pelanggan dan mendorong loyalitas pelanggannya.

5. Public relations Votrro telah berhasil melaksanakan visi/misi koultoura untuk mengedukasi customer.

\section{Simpulan}

Setelah melalui proses penelitian dan penulisan yang cukup panjang, maka skripsi ini dapat diselesaikan. Adapun saran yang dimiliki oleh peneliti terkait dengan institusi yang diteliti, dalam hal ini Votrro Coffee and Bar yaitu :

1. Public Relations Votrro agar memperluas jaringan untuk menginformasikan tentang Votrro Coffee and Bar sebaiknya mempunyai jaringan komunikasi lain selain Instagram.

2. Public Relations Votrro agar dapat meingkatkan kreatifitas dalam bentuk promosi untuk meningkatkan pembeli yang akan menambah keuntungan untuk Votrro dan loyalitasnya.

3. Public Relations Votrro dapat berkolaborasi dengan perusahaanperusahaan besar untuk melakukan promosi dengan mengadakan eventevent besar untuk meningkatkan brand pada khalayak luas.

Adapun saran akademis yang dimiliki oleh penulis untuk skripsi ini adalah bahwa nantinya penelitian ini dapat ditelaah secara lebih mendalam lagi mengenai kegiatan public relations yang dilakukan perusahaan lain, sehingga dapat dilihat perbedaan dan persamaan terhadap hasil penelitian nantinya. Selain itu, peneliti lain juga dapat menggunakan metode kuantitaif untuk menguji seberapa besar keterkaitan antara kegiatan public relations dengan loyalitas customer.

\section{Ucapan Terima Kasih}

Penulis mengucapakan terima kasih kepada seluruh narasumber yang telah bersedia untuk bekerja sama selama proses penelitian ini berlangsung. Ucapan terima kasih juga diberikan kepada Votrro Coffee and Bar yang telah memberikan ijin kepada penulis untuk melakukan penelitian. 
Jeffrey, Ahmad Junaedi: Kegiatan Public Relations Votrro Coffee And Bar Dalam Menjaga Loyalitas Customer Votrro Coffee And Bar

\section{Daftar Pustaka}

Jefkins, Frank. (2003). Public Relations, Edisi kelima, Jakarta: PT Gelora Aksara Pratama

Kasali, Rhenald. (2006). Pop Marketing dlam Konteks Pemasaran Indonesia. Jakarta : Gramedia Pustaka Utama.

Cutlip, Scott M., Center, Allen H., Broom, Glen M. (2005). Effective Public Relations, Edisi 8. Jakarta: PT Indeks Kelompok Gramedia.

Kriyantono. (2012). Public Relations \& Crisis Management: Pendekatan Critical Public Relations Etnografi Kritis \& Kualitatif. Jakarta: Kencana.

Mulyana, Deddy. (2007). Ilmu Komunikasi: Suatu Pengantar. Bandung : Remaja Rosdakarya.

Moleong, Lexy J. (2013). Metode Penelitian Kualitatif, Edisi Revisi. Bandung : PT. Remaja Rosdakarya. 